f. med. Genet. (1966). 3, 70.

\title{
Detection of Chromosomal Mosaicism by Computer Methods
}

\author{
JOHN F. JACKSON and PAUL E. PULLEY \\ From the Department of Preventive Medicine and the Computer Center, University of Mississippi Medical Center, \\ Fackson, Mississippi, U.S.A.
}

Modern techniques of cell culture have led to widespread use of chromosome analysis as a diagnostic tool in human disease. In normal subjects, variations of chromosome counts about the modal number are generally attributed to artefact. This assumption is supported by the fact that the distribution is negatively skewed around the modal number, logically attributable to loss of chromosomes from broken cells (Court Brown, Jacobs, and Doll, 1960). It is reasonable to suppose, however, that mitotic errors sometimes give rise to cells in somatic tissues with chromosome numbers other than the modal number. Non-disjunction during gametogenesis or in early cleavage stages of the zygote is probably the cause of most chromosomal abnormalities in man. Thus an occasional individual may be a mosaic, having some tissues composed of two or more stem-lines of cells with different chromosome numbers. The accurate detection of mosaicism is highly desirable in the ultimate evaluation of chromosomal abnormalities, especially in regard to potential variation in disease syndromes due to mosaicism. An even more pressing problem is the evaluation of parents of children with trisomy $2 \mathrm{I}$ (Down's syndrome or mongolism), since mosaicism in an apparently normal parent may account for an increased risk for bearing mongoloid offspring (Weinstein and Warkany, 1963).

The problem facing the cytogeneticist is when to suspect mosaicism and how to confirm or deny his suspicion. First, the number of cells with aneuploid counts must be more than can reasonably be expected by chance alone. Ideally, the excess of aneuploidy should be observed in two or more examinations, and in two or more tissues. Karyotype analysis should support the conclusion by providing evidence that a high proportion of the aneuploid cells have the same karyotype. Calcula-

Received April 12, I965. tions of the probability of finding aneuploi should give a clue to the presence of mosaicisism in any given individual chromosome analysis. Since culture techniques and criteria for accepting or rejecting individual cells for counting vary from one laboratory to another, probabilities should be established by each laboratory group to test the significance of its own data. Utilizing the IBM I I computer, we have calculated probabilities printed in the form of tables.

For this purpose, chromosome analyses from peripheral blood leucocyte cultures were divided into three groups: I. Normal, which included bogh truly normal individuals who had no known disease, and individuals with disease states in which no chromosomal abnormality was fourotid. 2. Abnormal other than cancer, which included oill individuals with a recognizable chromosonal abnormality. 3. Cancer cells.

In each group, cell counts were arranged 鹰 3 classifications: hypomodal, modal, and hypermodal, omitting polyploids. There were 3,088 cests scored in 69 chromosome analyses from the norrial group with a distribution of 0.0398 hypomodigl, 0.9378 modal, and 0.0223 hypermodal. There were 1,005 cells scored in 20 analyses from infividuals with chromosome abnormalities other than cancer, with a distribution of 0.0497 hypomodal, 0.9363 modal, and 0.0139 hypermodal. The additional cases were omitted, since they had been recognized as probably being mosaics. Probabilitis ss of selecting individual cell counts were calculaţed by the following formula: Let A, B, C, eqfal probabilities of modal, hypomodal, and hypermokal counts respectively with respective frequencies $a, b, c$, from a sample of size $n$, where $a+b+c$ e $\mathrm{n}$ and $\mathrm{A}+\mathrm{B}+\mathrm{C}=\mathrm{I}$. $\mathrm{A}, \mathrm{B}$, and $\mathrm{C}$ are derives

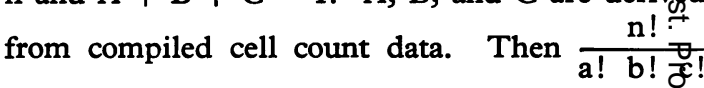
$\mathrm{A}^{\mathrm{a}} \mathrm{B}^{\mathrm{b}} \mathrm{C}^{\mathrm{c}}=\mathrm{P}=$ probability $(\mathrm{a}, \mathrm{b}, \mathrm{c})$ occurring chance alone. For practical application the formfla 
was programmed for the computer so that probability tables could be printed out at multiples of Io cells counted. The computer programme applicable to most computers and set to stop when $\mathbf{P}$ becomes consistently $<0.0000 \mathrm{I}$ is listed as programme I. This programme requires that the dominant probability be entered as the variable PA, corresponding to the modal population.

The counting of 30 cells as a minimum number for the determination of chromosome count Jacobs, McBride, and Tough, 196I). In the accompanying illustration, the computer print-out is shown for probabilities of finding individual cell counts within the framework of our laboratory technique. Column A is modal, B hypomodal, $C$ hypermodal; the next column is the possible number of combinations to arrive at such a count, and the final decimal figure is the probability for that individual count. Additional tables are printed at cell count levels of 40,50 , etc. Since the probabilities fall off so rapidly with decreasing numbers of modal cell counts, no more than 100 lines of print-out are necessary, even at the cell

PA $\quad 0.93780$ PB 0.03980 PC 0.02230 N 30 Normal

\begin{tabular}{|c|c|}
\hline $\begin{array}{ll}\text { A } & 30 \\
\text { A } 29 \\
\text { A } 29 \\
\text { A } 28 \\
\text { A } 28 \\
\text { A } 28 \\
\text { A } 27 \\
\text { A } 27 \\
\text { A } 27 \\
\text { A } 27 \\
\text { A } 26 \\
\text { A } 26 \\
\text { A } 26 \\
\text { A } 26 \\
\text { A } 26 \\
\text { A } 25 \\
\text { A } 25 \\
\text { A } 25 \\
\text { A } 25 \\
\text { A } 25 \\
\text { A } 25 \\
\text { A } 24 \\
\text { A } 24 \\
\text { A } 24 \\
\text { A } 24 \\
\text { A } 24 \\
\text { A } 24\end{array}$ & 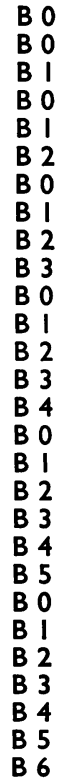 \\
\hline
\end{tabular}

$\begin{array}{ll}712530 . & 0.001408 \\ 1425060 & 0.005027\end{array}$

1425060. 0.00897 1

$712530 . \quad 0.008006$

142506. $\quad 0.002858$

593775. 0.000016

3562650 . $\quad 0.000167$

8906625. 0.000747

11875500 . $\quad 0.001778$

8906625. $\quad 0.002380$

3562650. $\quad 0.001699$

593775. $\quad 0.000505$ distribution has been generally accepted (Baikie,

\section{PROGRAMME I}

\begin{tabular}{|c|c|c|}
\hline Seq & STMNT & Fortran Statement \\
\hline $\begin{array}{l}1 \\
2 \\
3 \\
4\end{array}$ & $\begin{array}{r}1 \\
201\end{array}$ & $\begin{array}{l}\text { Dimension title (5) } \\
\text { Read IOI, PA, PB, PC, N, title } \\
\text { Print 20I, PA, PB, PC, N, title } \\
\text { Format (3HIPA, FI0.5, 3X, 2HPB, } \\
\text { FI0.5, 3X, 2HPC, FI0.5, 3X, I HN, }\end{array}$ \\
\hline
\end{tabular}
I5, 5X, 5A8)

I0I Format (3FI0.0, I5, 4X, 5A8)

Print 202

202 Format (IHO, 34X, 9HFrequency, 5X, 10HProbability)

$$
\text { IF (PA+PB + PC-1.0) 2, 2, } 16
$$

$P A L=\log F(P A)$

$P B L=\log F(P B)$

$P C L=\log F(P C)$

$\mathrm{FN}=\mathrm{N}$

$\mathrm{I}=0$

$J=0$

$K=0$

15

16

17

FIG. A portion of computer printed table listing probabilities for individual 30 cell counts to occur by chance alone, based on compiled laboratory data. 
count level of 90. Computer time is negligible, since the IBM I40I computer prints each line at approximately I-second intervals. To use the tables, one simply looks up the probability of finding any individual count, having counted 20 cells. If the probability of finding that count is within acceptable limits, then no further counts need to be made. Although the limits of probability must satisfy the individual investigator, $P$ values greater than 0.01 have been regarded as being within the limits of normal (Baikie et al., 196r). If a count produces a borderline probability, then successive ten cell counts can be added, and the corresponding tables consulted. If the proportion of aneuploidy previously found continues, then the probability that the analysis falls within the normal range becomes progressively less. Confirmation of any particular stem-line must of course be carried out by karyotyping cells of that line.

A similar computer programme was devised to determine probabilities for specific samples where the total number of cells counted was larger than would be feasible for print-out in tabular form. This formula includes an approximation of the combinatorial weight which increases in accuracy when each value for $a, b$, or $c$ is greater than 5 .

Let $\mathbf{X}=(n+\mathbf{I} / 2) \log _{\mathrm{e}} \mathrm{n}+\mathrm{a}\left[\log _{\mathrm{e}} \mathrm{A}-\log _{\mathrm{e}} \mathrm{a}\right]+$ b $\left[\log _{e} B-\log _{e} b\right]+c\left[\log _{e} C-\log _{e} c\right]-\log _{e}(2 \pi)-$ $\mathrm{I} / 2 \log _{\mathrm{e}}(\mathrm{abc})$ where $\mathrm{X} \leqq 0$.

Then probability $[a, b, c]=e^{x}$ where $\log _{e}$ and e have Naperian or natural base.

Note: $I / 2 \log _{e}(a b c)=I / 2\left[\log _{e} a+\log _{e} b+\log _{e} c\right]$. Other notations $\mathrm{A}, \mathrm{B}, \mathrm{C}$, etc. are the same as in the previous formula. To accommodate extremely low probabilities, the $\mathrm{E}$ format is used, so that answers appear as decimal figures followed by exponent values representing powers of 10 . This computer programme is listed as programme 2 .

The three cases from this laboratory suspected to be mosaics indicate the extremely low probabilities found in actual practice.

\section{Mongol}

Chromosomes per cell

Number of cells

$\mathbf{P}=0.49668839 \mathrm{E}-17=0.5 \times \mathrm{IO}^{-17}$.

2. Turner's syndrome

\begin{tabular}{lr|r|r|r|c} 
Chromosomes per cell & 44 & 45 & 46 & 47 & Total \\
Number of cells & 3 & 71 & 28 & I & 103
\end{tabular} $\mathrm{P}=0.36458727 \mathrm{E}-29=0.4 \times 10^{-29}$.

\section{Mongol}

Chromosomes per cell

Number of cells

\begin{tabular}{c|c|c|c}
45 & 46 & 47 & Total \\
\hline 2 & 10 & 19 & 31
\end{tabular}

$\mathbf{P}=0.36933054 \mathrm{E}-08=0.4 \times 10^{-8}$.

PROGRAMME 2

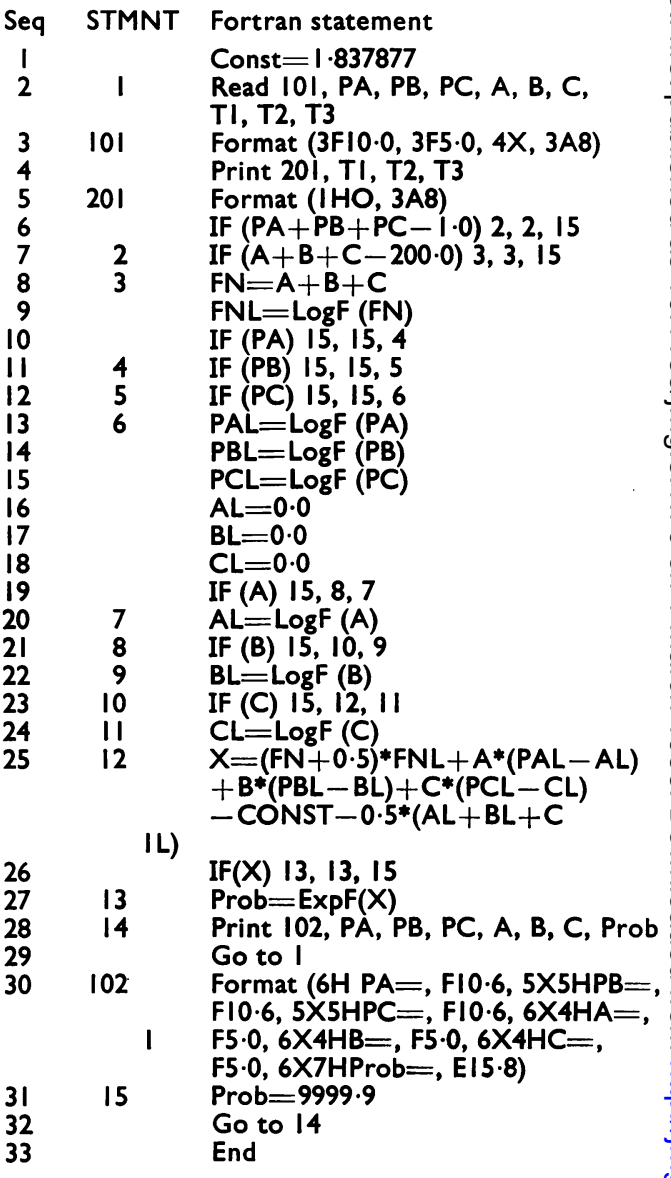

In the study of cancer cells, chromosome analyisis frequently indicates a modal number readify recognizable as being outside the range of normal without resort to statistical analysis. However, In malignant disease involving the haemopoie system, such as multiple myeloma, leukaem and Waldenstrom's macroglobulinaemia, pro bility estimates on specific results of chromosome counting may be helpful.

\section{Summary}

A computer programme was devised to prộnt tables of probabilities for obtaining specific eell counts in chromosome analysis. Utilizing the distribution of hypomodal, modal, and hypermofol counts obtained by any given laboratory, similar 
tables applicable to that laboratory can be conveniently printed by computer. Such tables should be helpful in the detection of mosaicism, and in the determination of an adequate sample size for any given analysis in which mosaicism is suspected.

This investigation was supported in part by Public Health Service Research Grant No. CA-07900-02 from the National Cancer Institute, and Grant 401 from the Children's Bureau, Welfare Administration, Department of Health, Education and Welfare.

\section{REPERENCES}

Baikie, A. G., Jacobs, P. A., McBride, J. A., and Tough, I. $M$. (196I) Cytogenetic studies in acute leukaemia. Brit. med. F., $I, 1564$.

Court Brown, W. M., Jacobs, P. A., and Doll, R. (1960). Interpretation of chromosome counts made on bone-marrow cells. Lancet, $1,160$.

Weinstein, E. D., and Warkany, J. (1963). Maternal mosaicism and Down's syndrome (mongolism). F. Pediat., 63, 599. 